\title{
The reliability and validity of the Diabetes Family Responsibility Questionnaire, in a sample of Swedish children with Type 1 diabetes and their parents
}

\author{
Peter Sand ${ }^{1}$, Anna Nilsson Kleiberg ${ }^{2}$, Gun Forsander ${ }^{1}$ \\ 1. Department of Pediatrics, Institute of Clinical Sciences, Sahlgrenska Academy at The University of Gothenburg, The \\ Queen Silvia Children's Hospital, Sahlgrenska University Hospital, Vårdalinstitutet, The Swedish Institute for Health \\ Sciences, Gothenburg, Sweden. 2. The Queen Silvia Children's Hospital, Sahlgrenska University Hospital, Gothenburg, \\ Sweden.
}

Correspondence: Peter Sand. Address: Department of Pediatrics, Institute of Clinical Sciences, Sahlgrenska Academy at The University of Gothenburg, Sweden. Email: peter.sand@vgregion.se.

Received: December 27, 2012 Accepted: May 1, $2013 \quad$ Online Published: July 24, 2013

DOI : 10.5430/jnep.v3n11p165 URL: http://dx.doi.org/10.5430/jnep.v3n11p165

\section{Abstract}

Study background: The Diabetes Family Responsibility Questionnaire (DFRQ) is a self-report questionnaire developed to measure family sharing of responsibility for diabetes treatment tasks. The Swedish version of the DFRQ is currently being used in an ongoing family intervention study at The Queen Silvia Children's hospital. Testing the reliability and validity of the instrument in a Swedish population is an important work in raising the quality of its contribution to research.

Aim: The overall aim of the study was to assess the psychometric properties of the DFRQ in a Swedish sample of children, mothers and fathers. A second aim was to bring fathers into the sample and to evaluate whether there are any differences in how mothers and fathers perceive family sharing of responsibility for diabetes treatment tasks.

Methods: 159 inhouse patients, 8-18 years, from two diabetes centres, and their parents, participated in the study. The DFRQ was administered by postal mail to the families. Internal consistency of the scale was measured with Cronbach's alpha and its concurrent validity was evaluated using bivariate correlations. Independent $t$-tests were performed to test for differences between mother- and father reports. The study was reviewed and approved by the Regional Ethical Review Board.

Results: The Diabetes Family Responsibility Questionnaire exceeded the criteria for satisfactory internal consistency for the child-, mother- and father reports with $\alpha$-values ranging from .87 to .90 . Furthermore, children and parents reported that the child assumed greater responsibility for diabetes management tasks with increasing age, thus confirming concurrent validity of the instrument.

Conclusion: In summary the study concludes that the Swedish version of the DFRQ can be utilized as a valuable tool both in a research setting and in clinical practice.

\section{Key words}

Responsibility, HbA1c, Type 1 diabetes, Children, Adolescents 


\section{Introduction}

Pediatric type 1 diabetes is a chronic disease that requires extensive medical management in order to keep blood glucose at normal levels. The child must coordinate insulin administration, blood glucose monitoring, dietary intake and intensity of physical activity ${ }^{[1]}$. Adherence to the daily treatment of diabetes necessitates cooperation and involvement from the family and places high demands on the sharing of roles and responsibilities around the diabetes management ${ }^{[2]}$. The roles of family members typically vary with the child's age and developmental level ${ }^{[3,4]}$. As the child grows older the question of transferring responsibility from the parent to the child will increasingly be in focus ${ }^{[2,5]}$. Youths in their early teens can perform the diabetes tasks by themselves, but they are still in need of support and supervision by their parents ${ }^{[5,6]}$. Actual age have influenced parents to transfer responsibility for diabetes tasks to youths when in fact cognitive maturity and being ready to assume responsibility for diabetes-management are essential predictors for the maintenance of a healthier metabolic control ${ }^{[7]}$. In families where the question of responsibility is well defined and shared, the glycemic control is more likely to be stable ${ }^{[3,4,8]}$. Shared responsibility has been shown to have positive outcomes for both the psychological and the physical health in the child ${ }^{[8,9]}$. One study found that the child's perception of shared responsibility was associated with less depression and less anger in the child as well as higher diabetes self efficacy and better self-care. Furthermore, for older adolescents the perception of shared responsibility was also associated to healthier metabolic control ${ }^{[8]}$. In a clinical setting it is important to be able to identify perceived responsibility around the diabetes management since this issue is shown to be related to diabetes outcomes ${ }^{[8]}$.

The Diabetes Family Responsibility Questionnaire (DFRQ) is a self-report questionnaire developed to measure family sharing of responsibility for diabetes treatment tasks. The DFRQ has good psychometric properties and has previously been reported to be strongly positively correlated to the child's age ${ }^{[5]}$. However, attention has been paid to the fact that samples often consist of a limited number of fathers, which typically may be a result of the recruitment of study participants at clinic appointments where mothers are overrepresented ${ }^{[10]}$. Apart from including more fathers in pediatric research there is also a need to analyze maternal and paternal effects separately ${ }^{[11]}$. The Swedish version of the DFRQ is currently being used in an ongoing family intervention study at The Queen Silvia Children's hospital. The intervention study design is randomized controlled trial. Families are followed up prospectively two years after the onset of type 1 diabetes, with regards to metabolic control and psychological factors. Testing the reliability and validity of the instrument in a Swedish population is an important work in raising the quality of its contribution to research. The DFRQ is also a valuable instrument in clinical settings. In the clinic it can be used as a basis for discussing with family members how they perceive responsibility sharing of diabetes management tasks and thereby also raising the awareness for potential problem areas, for example tasks for which no one takes on responsibility.

\section{Aim}

The aim of this study was to demonstrate the psychometric properties of the Swedish version of the DFRQ by assessing the reliability with Cronbach's Alpha and performing a limited validation using predictive validity in a sample including both mothers and fathers. A second aim was to bring fathers into the sample and to evaluate whether there are any differences in how mothers and fathers perceive family sharing of responsibility for diabetes treatment tasks.

\section{Method}

\subsection{Study design}

The study had a cross-sectional design and was conducted as a survey.

\subsection{Participants}

Data was collected among inhouse patients at two pediatric diabetes centres in Sweden. The sample consisted of in total 318 children and adolescents and their parents. Eligibility criteria included; current age 8-18 years, fluency in the Swedish 
language and duration of type 1 diabetes for at least 6 months. Children with developmental disability and/or mental retardation were excluded as well as children with another significant medical disease other than type 1 diabetes, celiac disease and thyroid disorders. Of the 318 families who met the eligibility criteria $159(50 \%)$ agreed to participate in the study.

\subsection{Procedure}

Families were invited via an information letter that was sent out in a mailing together with the DFRQ questionnaire. The mailings were administered by especially assigned research coordinators, one from each pediatric centre. The research coordinators had previous to the mailing procedure received detailed verbal and written instructions from the research team. A new mailing was sent out with a reminder to the families who had not answered the first mailing within three weeks. Each family member received the DFRQ, an information letter and a letter of consent. In addition each family was asked to fill out background variables on the child such as sex, current age and age at diabetes onset. The most recent $\mathrm{HbA1c}$ value was retrieved by the especially assigned research nurses from the child's diabetes centre.

\subsection{Measures}

Each child and parent independently answered the Swedish version of the DFRQ, originally developed for children aged 8-18 and their parents ${ }^{[5]}$. The instrument had previously been translated into Swedish using forward and backward translation in order to ensure conceptual equivalence ${ }^{[12]}$. The DFRQ measures the degree of parent involvement on 17 diabetes management tasks such as insulin administration, checking blood glucose values, and telling others about diabetes. Each task is rated by the respondent as belonging primarily to the parent (score 1), being shared equally by the parent and child (score 2), or belonging primarily to the child (score 3), with the total score ranging from 17 to 51, with higher scores indicating that the child assumes greater responsibility. Acceptable internal consistency has previously been reported for the DFRQ scale with youth coefficients ranging from $\alpha=.72$ to $\alpha=.78$, and parent coefficients ranging from $\alpha$ $=.67$ to $\alpha=.85^{[3,4,9,13,14]}$.

Child and adolescent blood glucose control (i.e HbA1c values) was retrieved from the medical charts. HbA1c was measured locally with DCA Vantage, calibrated according to the national Swedish standard, IFCC ( $\mathrm{mmol} / \mathrm{mol})$ with a normal value 27-42. All centres participated in a national HbA1c quality control system (EQUALIS) and there was no deviation from the set targets during the study period.

\subsection{Statistical analysis}

The SPSS version 20 for Windows was used for all statistical analysis. Descriptive statistics were calculated for the background variables sex, age, and diabetes duration. Internal consistency of the DFRQ was assessed with Cronbach's $\alpha$ for the child-, mother- and father reports in order to ensure that the items in the scale measure the same underlying concept. Alpha values above .70 were considered as acceptable ${ }^{[15]}$. Bivariate correlations between the child's age and the degree of child responsibility for diabetes management tasks, as reported by the children, mothers, and fathers were conducted in order to evaluate the concurrent validity of the DFRQ. The independent contribution of age on responsibility, as reported by mother, father and child, was finally examined in a hierarchical multi regression model, with the demographic variables gender, age, and diabetes duration added as independent variables in the second model, since these variables are usually associated with glycemic control. An independent samples t-test was finally used to test for differences in mothers' and fathers' reported levels of responsibility.

\subsection{Ethical considerations}

The study was reviewed and approved by the Regional Ethical Review Board. The data obtained from the participants was used exclusively in this study. Participants were anonymous to the authors thus ensuring confidentiality. The diabetes onset often promotes a crisis in the family which together with the adaption to a new life style may make the first months after onset very burdensome. The inclusion criteria, duration of type 1 diabetes for at least 6 months, was decided upon 
with this initial period of crisis and adaption in mind, taking into account ethical considerations as well as the fact that family functioning in the first period after onset may not be representative.

\section{Results}

\subsection{Descriptive statistics and glycemic control}

As shown in table 1, mean age for the responding children in the sample was 13.5 years and mean age at diabetes onset was 6.0 years. $54 \%$ of the participating children were boys. HbAlc values ranged from 35 to $89 \mathrm{mmol} / \mathrm{mol}$ with a mean of $61.1 \mathrm{mmol} / \mathrm{mol}$.

Table 1. Sample characteristics. Responders

\begin{tabular}{lllll}
\hline Characteristics & & Mean & SD & Range \\
\hline $\mathbf{N}$ & 159 & & & \\
Sex (\% male) & 53.5 & 13.5 & 2.8 & $8-18$ \\
Age (years) & & 6.0 & 3.7 & $0.5-15.5$ \\
Diabetes duration (years) & & 61.1 & 11.2 & $35-89$ \\
HbA1C (mmol/mol) & & & & \\
\hline
\end{tabular}

\subsection{I nternal consistency}

In this sample Cronbach's alpha exceeded .70 for both child- and parent reports with levels at $\alpha=.87$ (child), $\alpha=.90$ (mother), and $\alpha=.87$ (father), suggesting that the instrument has high internal consistency.

\subsection{Concurrent validity: Responsibility sharing and age}

The relationship between responsibility sharing (as measured by the DFRQ) and the child's age was investigated using the Pearson product-moment correlation coefficient. The analysis revealed that child-, mother- and father reports of responsibility sharing were significantly positively correlated with the child's age, indicating that children assume greater responsibility for diabetes management tasks with increasing age. This correlation was strong for both child- and parent reports; $\mathrm{r}=.76, p<.000$ (child), $\mathrm{r}=.76, p<.000$ (mother) and $\mathrm{r}=.68, p=.000$ (father), thus confirming the concurrent validity of the instrument. Three separate two model hierarchical regressions were performed to assess the independent contribution of age on responsibility, as reported by mother, father and child, after controlling for the influence of gender, $\mathrm{HbA1C}$ and diabetes duration. All models were significant at the .000 level. The additional influence of gender, diabetes duration and $\mathrm{HbAlc}$ did not have any significant effect on responsibility as reported by mother and child (see Table 2). In the fathers regression model diabetes duration and $\mathrm{HbAlc}$ did have a significant contribution, explaining an additional 8.1 $\%$ of the variance in responsibility. Bivariate correlations between father reported responsibility and diabetes duration and between father reported responsibility and HbAlc were however not significant.

\subsection{Mother's and father's reports of conflict}

There was no significant difference between mothers' and fathers' reports on responsibility on the total scale (mean 33.13 for mothers vs 33.48 for fathers).

\section{Discussion}

This study examined the psychometric properties of the Swedish version of the DFRQ. The total scale exceeded the criteria for satisfactory internal consistency for the child-, mother- and father reports, with $\alpha$-values ranging from .87 to .90. These results are in line with previous reports on the DFRQ and confirm the reliability of the Swedish version of the scale $^{[3-5,9,13,14]}$. 
Table 2. Hierarchical Regression Analysis

\begin{tabular}{|c|c|c|c|c|}
\hline & $\beta$ & $\mathrm{T}$ & $\Delta \mathrm{R}^{2}$ & $\mathrm{R}^{2}$ \\
\hline \multicolumn{5}{|l|}{ Child report } \\
\hline \multicolumn{5}{|c|}{ Dependent variable Responsibility } \\
\hline Model 1 & & & & $0.57 * *$ \\
\hline Age & 0.76 & $13.30 * *$ & & \\
\hline Model 2 & & & 0.02 & 0.59 \\
\hline Age & 0.79 & $12.85 * *$ & & \\
\hline Gender & -0.10 & -1.80 & & \\
\hline Diabetes duration & -0.07 & -1.10 & & \\
\hline $\mathrm{HbA} 1 \mathrm{C}$ & 0.06 & -1.09 & & \\
\hline \multicolumn{5}{|l|}{ Mother report } \\
\hline \multicolumn{5}{|c|}{ Dependent variable Responsibility } \\
\hline Model 1 & & & & $0.57 * *$ \\
\hline Age & 0.76 & $13.28 * *$ & & \\
\hline Model 2 & & & 0.02 & 0.59 \\
\hline Age & 0.80 & $12.94 * *$ & & \\
\hline Gender & -0.09 & -1.50 & & \\
\hline Diabetes duration & -0.10 & -1.58 & & \\
\hline $\mathrm{HbA1C}$ & -0.03 & -0.48 & & \\
\hline \multicolumn{5}{|l|}{ Father report } \\
\hline \multicolumn{5}{|c|}{ Dependent variable Responsibility } \\
\hline Model 1 & & & & $0.46^{* *}$ \\
\hline Age & 0.68 & $10.61 * *$ & & \\
\hline Model 2 & & & 0.08 & $0.54 * *$ \\
\hline Age & 0.79 & $12.04 * *$ & & \\
\hline Gender & -0.10 & -1.65 & & \\
\hline Diabetes duration & -0.23 & $-3.44 * *$ & & \\
\hline $\mathrm{HbA} 1 \mathrm{C}$ & -0.15 & $-2.48^{*}$ & & \\
\hline
\end{tabular}

${ }^{* *} p<.01 ;{ }^{*} p<.05$

The analysis furthermore confirmed the concurrent validity of the Swedish version of the DFRQ with a higher degree of reported responsibility taking by the child being associated with the child's increasing age. This was true for child-, mother- and father reports, indicating that older children assume greater responsibility for diabetes management tasks. These findings are consistent with previous research and thus add to the accumulated knowledge on the association between the responsibility sharing in diabetes management and the child's age. The results suggest that it is the child's chronological age that influences parents to transfer responsibility on to the child rather than the child's cognitive maturity and actual ability to assume such responsibility. Previous research has shown that children assuming a greater degree of responsibility for diabetes tasks have poorer metabolic control than children who assume less responsibility ${ }^{[16,17]}$. This could be a result of the child not being ready to assume the degree of responsibility of diabetes management that is transferred to him or her and that there is a lack of parental support in the transition ${ }^{[14]}$.

In contrast to previous research in the same field this study brought both mothers and fathers into the sample, enabling separate analyses of their reports ${ }^{[10,11]}$. Both mother and father reports of responsibility sharing had strong correlations with the child's age. There was no difference between mothers and fathers reports of responsibility suggesting that mother's and father's have similar experiences of responsibility around diabetes related diabetes management tasks. The equal response rate of mothers and fathers may be a reflection of the Swedish National Pediatric Diabetes Guidelines for children and adolescents with diabetes, which advocates that both parents should be involved in the process of the diabetes management. This common engagement in the child's medical treatment is also enabled by a dual-breadwinner norm and the Swedish parental leave system ${ }^{[18-20]}$. 


\section{Limitations of the study}

The present study has some limitations. Only $50 \%$ of the families agreed to participate in the study. The postal administeration of the questionnaires may have influenced the willingness to participate $\mathrm{A}$ face-to-face administration may have been less burdensome to the respondents and thus motivated higher participation. Another implication of the postal administration is the lack of control over how well families have met the instructions that the questionnaires are to be answered independently by family members. Especially in families with younger children there may have been cases with parents helping out children. Another limitation is the lack of descriptive data on the parents. Demographic factors such as family size, age, income, and occupation of the parents could influence reported results and would have been interesting to take into account in the analysis. Finally the cross-sectional design of this study poses a limitation that needs to be taken into consideration in the interpretation of the results ${ }^{[21]}$.

\section{I mplications for practice}

The DFRQ is a valuable tool in a clinical setting considering that it is the child's age more often than his or her current cognitive and emotional maturity that underlies parents transfer of responsibility, and that children assuming a greater degree of responsibility for diabetes tasks have been shown to have poorer metabolic control ${ }^{[16,17]}$. The instrument can help raise the awareness in families on how responsibility sharing is functioning as well as serve as a screening instrument for physicians as part of the medical follow up.

\section{Conclusion}

In summary the study concludes that the Swedish version of the DFRQ has acceptable psychometric properties and can be utilized as a valuable tool both in a research setting and in clinical practice. In a clinical setting the DFRQ can be a helpful tool for identifying how responsibility for diabetes management tasks are shared within the family and for facilitating the communication between family members around responsibility issues.

\section{Acknowledgement}

The authors would like to thank the coordinators Birgitta Blank (RN) at Falun Lasarett and Rosita Ilvered (RN) at Länssjukhuset Ryhov for their assistance in the study. This study was supported by Vårdalinstitutet, The Swedish Institute for Health Sciences, Magnus Bergvalls Foundation, and The Swedish Child Diabetes Foundation.

\section{Competing interests}

The authors declare that they have no competing interests.

\section{References}

[1] Silverstein J, Klingensmith G, Copeland K, Plotnick L, Kaufman F, Laffel L, et al. Care of children and adolescents with type 1 diabetes: a statement of the American Diabetes Association. Diabetes Care. 2005 Jan; 28(1): 186-212. PMid:15616254 http://dx.doi.org/10.2337/diacare.28.1.186

[2] Drotar D, Ievers C. Age differences in parent and child responsibilities for management of cystic fibrosis and insulin-dependent diabetes mellitus. J Dev Behav Pediatr. 1994 Aug; 15(4): 265-72. PMid:7798372 http://dx.doi.org/10.1097/00004703-199408000-00008

[3] Ingerski LM, Anderson BJ, Dolan LM, Hood KK. Blood glucose monitoring and glycemic control in adolescence: contribution of diabetes-specific responsibility and family conflict. J Adolesc Health. 2010 Aug; 47(2): 191-7. PMid:20638012

http://dx.doi.org/10.1016/j.jadohealth.2010.01.012 
[4] Vesco AT, Anderson BJ, Laffel LM, Dolan LM, Ingerski LM, Hood KK. Responsibility sharing between adolescents with type 1 diabetes and their caregivers: importance of adolescent perceptions on diabetes management and control. J Pediatr Psychol. 2010 Nov; 35(10): 1168-77. PMid:20444852 http://dx.doi.org/10.1093/jpepsy/jsq038

[5] Anderson BJ, Auslander WF, Jung KC, Miller JP, Santiago JV. Assessing family sharing of diabetes responsibilities. J Pediatr Psychol. 1990 Aug; 15(4): 477-92. PMid:2258796 http://dx.doi.org/10.1093/jpepsy/15.4.477

[6] Wysocki T, Taylor A, Hough BS, Linscheid TR, Yeates KO, Naglieri JA. Deviation from developmentally appropriate self-care autonomy. Association with diabetes outcomes. Diabetes Care. 1996 Feb; 19(2): 119-25. PMid:8718430 http://dx.doi.org/10.2337/diacare.19.2.119

[7] Ingersoll GM, Orr DP, Herrold AJ, Golden MP. Cognitive maturity and self-management among adolescents with insulin-dependent diabetes mellitus. J Pediatr. 1986 Apr; 108(4): 620-3. http://dx.doi.org/10.1016/S0022-3476(86)80852-6

[8] Helgeson VS, Reynolds KA, Siminerio L, Escobar O, Becker D. Parent and adolescent distribution of responsibility for diabetes self-care: links to health outcomes. J Pediatr Psychol. 2008 Jun; 33(5): 497-508. PMid:17848390 http://dx.doi.org/10.1093/jpepsy/jsm081

[9] Hsin O, La Greca AM, Valenzuela J, Moine CT, Delamater A. Adherence and glycemic control among Hispanic youth with type 1 diabetes: role of family involvement and acculturation. J Pediatr Psychol. 2010 Mar; 35(2): 156-66. PMid:19491214 http://dx.doi.org/10.1093/jpepsy/jsp045

[10] Belendez M, de Wit M, Snoek FJ. Assessment of parent-adolescent partnership in diabetes care: a review of measures. Diabetes Educ. 2010 Mar-Apr; 36(2): 205-15. PMid:20130166 http://dx.doi.org/10.1177/0145721709359205

[11] Phares V, Lopez E, Fields S, Kamboukos D, Duhig AM. Are fathers involved in pediatric psychology research and treatment? J Pediatr Psychol. 2005 Dec; 30(8): 631-43. PMid:15772363 http://dx.doi.org/10.1093/jpepsy/jsi050

[12] White M, Elander G. Translation of an instrument. The US-Nordic Family Dynamics Nursing Research Project. Scand J Caring Sci. 1992; 6(3): 161-4. PMid:1439377 http://dx.doi.org/10.1111/j.1471-6712.1992.tb00145.x

[13] Anderson BJ, Holmbeck G, Iannotti RJ, McKay SV, Lochrie A, Volkening LK, et al. Dyadic measures of the parent-child relationship during the transition to adolescence and glycemic control in children with type 1 diabetes. Fam Syst Health. 2009 Jun; 27(2): 141-52. PMid:19630455 http://dx.doi.org/10.1037/a0015759

[14] Cameron FJ, Skinner TC, de Beaufort CE, Hoey H, Swift PG, Aanstoot H, et al. Are family factors universally related to metabolic outcomes in adolescents with Type 1 diabetes? Diabet Med. 2008 Apr; 25(4): 463-8. PMid:18294223 http://dx.doi.org/10.1111/j.1464-5491.2008.02399.x

[15] Cronbach LJ, Coefficient alpha and the internal structures of tests. Psychometrika. 1951; 16: 297-334. http://dx.doi.org/10.1007/BF02310555

[16] Allen DA, Tennen H, McGrade BJ, Affleck G, Ratzan S. Parent and child perceptions of the management of juvenile diabetes. J Pediatr Psychol. 1983 Jun; 8(2): 129-41. PMid:6875761 http://dx.doi.org/10.1093/jpepsy/8.2.129

[17] La Greca AM, Behavioral aspects of diabetes management in children and adolescents. Diabetes. 1982; $32(2): 47$.

[18] Svensk författningssamling, 1995: 584.

[19] Sjöblad S, Barn-och ungdomsdiabetes. 2008.

[20] The Swedish Delegation for Gender Equality in School. 2009. Available from: http://www.regeringen.se/sb/d/108/a129434.

[21] Bowling A. Mode of questionnaire administration can have serious effects on data quality. J Public Health (Oxf). 2005 Sep; 27(3): 281-91. PMid:15870099 http://dx.doi.org/10.1093/pubmed/fdi031 